\title{
O ENSINO DE GRAMÁTICA A PARTIR DA ANÁLISE DA PROPOSTA PEDAGÓGICA DE LUIZ CARLOS TRAVAGLIA
}

\author{
GRAMMAR TEACHING FROM THE ANALYSIS OF LUIZ \\ CARLOS TRAVAGLIA'S PEDAGOGICAL PROPOSAL
}

\author{
Marcelo Alessandro Limeira dos ANJOS ${ }^{1}$ \\ Meryane Sousa OLIVEIRA ${ }^{2}$ \\ Raimunda da Conceição SILVA ${ }^{3}$
}

Resumo: Este artigo objetiva contribuir com o debate sobre o ensino de gramática, a partir da análise da proposta pedagógica de Luiz Carlos Travaglia na obra Na trilha da gramática: conhecimento linguístico na alfabetização e letramento (2013), levando em conta a exposição de motivos feita pelo autor na introdução de seu livro, com o intuito de verificar a exequibilidade e a pertinência de sua proposta para o ensino da "comparação", discussão disposta no capítulo 2 da obra. Para tanto, partiu-se de discussões sobre o ensino de gramática no Brasil, com base nas ideias de Mattos e Silva (2004), Leite (2014), Faraco (2006, 2017), Borges Neto (2013, 2018), dentre outros, bem como nas orientações postuladas pelos documentos oficiais, como os PCN (1998) e a BNCC (2017). As análises apontam para o fato de que a proposta em tela, embora estabeleça um avanço teórico no debate de como enfrentar pedagogicamente a atividade metalinguística, não cumpre o propósito geral da obra (desenvolver a competência comunicativa dos alunos), haja vista que os exercícios de natureza estruturalista, que pouco estimulam o desenvolvimento das habilidades de leitura e de escrita como práticas sociais, prevalecem.

Palavras-chave: Ensino de gramática. Alfabetização. Letramento. Língua Portuguesa.
Abstract: This article has as objective to contribute to the debate regarding the grammar teaching from the analysis of Luiz Carlos Travaglia's pedagogical proposal on the book $\mathrm{Na}$ trilha da gramática: conhecimento linguístico na alfabetização e letramento (2013), taking into account the exposure of reasons made by the author on his book's introduction, with the purpose of verifying the feasibility and the relevance of his proposal for teaching "comparison", discussion set on the second chapter of his work. To this end, discussions about the grammar teaching in Brazil were taken as a starting point, grounded by ideas of Mattos and Silva (2004), Leite (2014), Faraco (2006, 2017), Borges Neto (2013, 2018), among others, as well as on the orientations postulated by official documents, like the PCN (1998) and the BNCC (2017). The analysis point to the fact that the screened proposal, although establishes a theoretical advance in the debate on how to pedagogically face the metalinguistic activity, do not fulfill the general purpose of the work (to develop the student's communicative competences), considering that what indeed prevails are the exercises with a structuralist nature which stimulate only a little the development of the reading and writing abilities as social practices.

Keywords: Grammar teaching. Alphabetization. Literacy. Portuguese Language.

\section{Universidade Federal do Piauí (UFPI),Teresina, Piauí, Brasil; marcelodosanjos@ufpi.edu.br; https://orcid.org/0000-0001-9151-2658}

2 Universidade Federal do Piauí (UFPI), Teresina, Piauí, Brasil; meryaneoliveira@yahoo.com.br; https://orcid.org/0000-0002-8267-1646

3 Universidade Federal do Piauí (UFPI), Teresina, Piauí, Brasil; rai-teresina81@hotmail.com; https://orcid.org/0000-0002-3089-7942 


\section{Introdução}

O ensino de língua materna, no Brasil, conforme Borges Neto (2018), desde os anos finais da década de 1960, vem sendo objeto de discussão e de crítica de vários linguistas e especialistas da área de Língua Portuguesa, tendo em vista a ênfase que ainda é dada ao modus operandi tradicional que norteia esse ensino, o qual é centrado, geralmente, na mera transmissão da nomenclatura gramatical e de seus conceitos, bem como em exercícios de reconhecimento e classificação de palavras e de funções sintáticas. Esse destaque dado ao ensino de gramática, no geral, não leva em conta os inúmeros estudos linguísticos e propostas pedagógicas que sugerem um ensino de Português pautado na reflexão sobre as várias possibilidades expressivas que a língua oferece, como é o caso da proposta de Geraldi (2011 [1997]), de Antunes (2003), de Neves (2018), de Perini (2016) e de Borges Neto (2013), só para citar alguns.

Ao refletir sobre o ensino de gramática no Brasil, Faraco (2017) chama a atenção para o fato de que, embora haja uma grande leva de estudos e propostas para um ensino de Língua Portuguesa que vai além do reconhecimento e da classificação da nomenclatura gramatical, o debate de como enfrentar pedagogicamente a atividade metalinguística ainda parece incipiente.

Conforme Faraco (2017, p. 20), está claro que, "apesar de termos clareza conceitual quanto à reconfiguração do ensino de natureza gramatical, há ainda grandes lacunas, em especial quanto à sistematização das propostas para além das asserções gerais". Ainda com o autor, as lacunas são questões cruciais que continuam ou sem respostas ou respondidas parcialmente, tais como: 1) Que temas merecem sistematização? 2) Em que momento e em que progressão? 3) Que quadros teóricos poderão ser relevantes na organização dessa atividade? 4) Que nomenclatura adotar? Abandonar a NGB ou adotá-la, considerando que ela está naturalizada $a^{4}$ na linguística, no discurso e no senso comum? 5) Proceder didaticamente por transmissão ou por descoberta?

Como já dito, ao longo dos anos, muitos linguistas vêm apresentando propostas pedagógicas para o ensino de Português que buscam superar algumas das lacunas supramencionadas, embora isso seja uma tarefa complexa. A obra Na trilha da gramática: conhecimento linguístico na alfabetização e letramento, de Travaglia (2013), inclui-se nesse vasto universo de publicações que buscam dar respostas a essas questões.

4 Para saber mais sobre a questão da naturalização da gramática tradicional, ver Borges Neto (2013). 
Com base nesses pressupostos, este artigo se propõe a contribuir com o debate sobre o ensino de gramática, a partir da análise da proposta pedagógica de Travaglia (2013), levando em conta a exposição de motivos feita pelo autor na introdução de seu livro, com o intuito de verificar a exequibilidade e a pertinência de sua proposta para o ensino da "comparação", discussão disposta no capítulo 2 da obra. No livro analisado, é importante antecipar, Travaglia busca orientar o professor sobre como fazer o ensino de gramática nas séries iniciais do Ensino Fundamental, com foco em uma alfabetização e letramento mais efetivos.

O próximo tópico traz uma breve discussão, baseada em uma perspectiva histórica, acerca do ensino de gramática, partindo de um contexto mais geral para o contexto brasileiro.

\section{Gramática e ensino: uma história de (des)continuidades}

O ensino de gramática, tal como se apresenta hoje, é resultado de uma série de processos históricos e socioculturais que, no geral, não são reconhecidos por muitos professores de Língua Portuguesa. Esse não reconhecimento desses processos que envolvem o objeto gramática implica diretamente um ensino reducionista. Isso porque, de acordo com Leite (2014, p. 116), a gramática não se reduz, como alardeiam os que não a conhecem, "a condenações de usos considerados indevidos ou proibidos, à divulgação de lições preconceituosas e intolerantes sobre a língua comum, praticada em geral pelos usuários de uma língua histórica, em gêneros primários ou secundários, na modalidade falada ou escrita".

Ao refletir sobre os processos históricos que afetaram o papel da gramática no ensino da língua, Faraco (2006), considerando que a gramática constitui-se como um entrave na vida escolar da maioria dos estudantes brasileiros, assevera que entender a história desse objeto, bem como as suas razões de ser, é a melhor forma de os professores superarem a "síndrome do erro" e passarem a criar condições para um ensino de Língua Portuguesa mais eficaz. A história, segundo o referido autor, desmistifica a gramática, reduzindo-a a suas reais proporções, de modo que é possível "dar nova direção ao ensino da nossa língua, atendendo, de fato, às necessidades socioculturais da população brasileira" (FARACO, 2006, p. 16).

A relação entre gramática e escola remonta aos gregos alexandrinos, os quais foram responsáveis por criar, no contexto do século II a.C., a disciplina gramática junto aos estudos de filologia (FARACO, 2017). Desse modo, a gramática nasceu vinculada à 
- O ensino de gramática a partir da análise da proposta pedagógica de Luiz Carlos Travaglia

filologia, incorporando um viés filosófico e, posteriormente, agregando conteúdos retirados da retórica.

Para Borges Neto (2018), a primeira gramática de que se tem notícia e que estabeleceu um modelo normativo de descrição foi a Tékhnē Grammatikē (tékhnē: arte, técnica; grammatikē: gramática), cuja autoria é atribuída a Dionísio Trácio (170 a.C. - 90 a.C.). Nesse sentido, o cunho normativo da gramática - a qual tinha, como objeto, a língua escrita dos poetas e prosadores do passado - justifica-se pelo fato de que "a sua função era a de expor sistematicamente a língua grega em que foram produzidas as obras clássicas, como elemento auxiliar da crítica literária" (BORGES NETO, 2018, p. 50).

Fazendo referência a Marco Fábio Quintiliano (30 d.C. - 95 d.C.), Borges Neto (2018) pontua que a principal obra deste autor, Institutio Oratoria, foi largamente usada no contexto da Idade Média e do Renascimento, de modo que a gramática - entendida como "arte" (saber prático) - era considerada apenas uma disciplina auxiliar da análise literária, portanto, era articulada com a leitura, com o estudo e com o comentário dos textos dos poetas e prosadores de prestígio.

O ensino de gramática passou por longos processos de mudanças em alguns momentos da história, na medida em que algo era acrescentado, diminuído, substituído ou suplantando (cf. LEITE, 2014). De acordo com Faraco (2017), essa concepção de educação proposta por Quintiliano, que entendia a gramática como uma disciplina auxiliar e funcional, deixa de ser seguida (em parte), de modo que esta disciplina passa a ganhar um lugar de destaque na educação linguística, devido a alterações do panorama sociolinguístico da Europa ocidental, após o fim do império romano do Ocidente.

A pedagogia medieval, que colocava a gramática no centro do ensino, esteve presente na Ratio Studiorum ${ }^{6}$, cujo foco da educação era o ensino da gramática do latim clássico, embora previsse um currículo que levasse em conta as artes liberais (gramática e retórica em particular), destacando a importância das atividades de leitura, escrita e oralidade. Vale observar, ainda com este autor, que havia também uma proibição explícita quanto ao uso da língua materna dos alunos no ensino (FARACO, 2017).

5 A gramática de Dionísio organiza-se nos moldes das tékhnai, configurando-se como um manual de gramática para o entendimento dos clássicos literários e a preservação da língua nele registrada. No contexto grego clássico, as tékhnai (plural de tékhnē) traziam definições dos objetos de determinada área, como a medicina, a retórica e a gramática, e as exemplificava (VIEIRA, 2018).

6 “Documento que, publicado em 1599, consolidou as diretrizes educacionais para os inúmeros colégios dos jesuítas na Europa e fora dela" (cf. Te jesuit Ratio Studiorum of 1599) (FARACO, 2017, p. 14). 
Em uma linha de descontinuidade com a pedagogia medieval da Ratio Studiorum e aproximando-se do que postulava Quintiliano, esteve Comênio (1592-1670), autor de Didática Magna7 (1627). Isso porque a proposta de Comênio, segundo Vieira (2015), baseava-se em uma metodologia de ensino centrada na leitura dos "bons autores" e não na análise gramatical por ela mesma. Nesse sentido, a educação básica deveria ser realizada primordialmente na língua materna dos alunos e não em latim, "o que valorizou as línguas modernas ao mesmo tempo em que rompeu com a tradição pedagógica medieval, que tinha o latim como língua de ensino e como objeto central da educação linguística" (VIEIRA, 2015, p. 122).

Trazendo a discussão para o contexto mais atual e considerando os pressupostos de Quintiliano e Comênio, é válido ressaltar que a proposta pedagógica de ensino de gramática enquanto um conhecimento complementar e auxiliar, articulado à leitura e à produção de texto, se faz presente nos documentos oficiais, como nos Parâmetros Curriculares Nacionais ${ }^{8}$ - PCN (1998) e, mais recentemente, na Base Nacional Comum Curricular $^{9}$ - BNCC (homologada em 2017). Contudo, embora esses documentos oficiais postulem um ensino de gramática contextualizado e articulado com o desenvolvimento de outras habilidades, é nítido que o modelo que é mais reproduzido nas escolas brasileiras de educação básica é o tradicional, cujo foco está na gramática por ela mesma, sem reflexão, conforme as concepções delineadas na Ratio Studiorum.

Com base no exposto, fica claro que o processo histórico da educação linguística, desde a Antiguidade até o século XVII, "deu forma a três postulações pedagógicas referentes ao ensino de gramática: seu estudo deve ser complementar e funcional (Quintiliano); seu estudo deve ocupar o centro do ensino (Ratio Studiorum); seu estudo é quase dispensável (Comênio)" (FARACO, 2017, p. 15).

\footnotetext{
7 "Livro que foi publicado em 1627 em tcheco e em 1631 em latim e é considerado o primeiro tratado pedagógico moderno" (ibidem, p. 15).

8 "Assim, não se justifica tratar o ensino gramatical desarticulado das práticas de linguagem. É o caso, por exemplo, da gramática que, ensinada de forma descontextualizada, tornou-se emblemática de um conteúdo estritamente escolar, do tipo que só serve para ir bem na prova e passar de ano - uma prática pedagógica que vai da metalíngua para a língua por meio de exemplificação, exercícios de reconhecimento e memorização de terminologia. Em função disso, discute-se se há ou não necessidade de ensinar gramática. Mas essa é uma falsa questão: a questão verdadeira é o que, para que e como ensiná-la" (BRASIL, 1998, p. 28).

9 “[...] os eixos de integração considerados na BNCC de Língua Portuguesa são aqueles já consagrados nos documentos curriculares da Área, correspondentes às práticas de linguagem: oralidade, leitura/escuta, produção (escrita e multissemiótica) e análise linguística/semiótica (que envolve conhecimentos linguísticos - sobre o sistema de escrita, o sistema da língua e a norma-padrão -, textuais, discursivos e sobre os modos de organização e os elementos de outras semioses)" (BRASIL, 2017, p. 69, grifo no original).
} 
Considerando o ensino de gramática no contexto brasileiro atual, é evidente que há uma tendência maior em seguir uma concepção tradicional, embora haja muitas propostas pedagógicas que tentam evidenciar um ensino focado no desenvolvimento da tríade leitura, escrita e oralidade, articulada ao ensino de gramática, como um meio de levar o aluno a refletir sobre a sua forma de organização e uso em diferentes contextos de produção.

Ao se pensar em um ensino de língua materna pautado na reflexão sobre os recursos que a língua oferece, a proposta de Geraldi (2011 [1997]), de incluir o eixo da análise linguística no ensino de Língua Portuguesa, é uma das que mais se destaca desde 1980 (cf. COSTA-HÜBES, 2010). Nas palavras de Geraldi (2011 [1997], p. 47):

A análise lingüística inclui tanto o trabalho sobre as questões tradicionais da gramática quanto questões amplas a propósito do texto; adequação do texto aos objetivos pretendidos; análise dos recursos expressivos utilizados (metáforas, metonímias, paráfrases, citações, discursos direto e indireto, etc.); organização e inclusão de informações etc. Essencialmente, a prática de análise lingüística não poderá limitar-se à higienização do texto do aluno em seus aspectos gramaticais e ortográficos, limitando-se a 'correções'. Trata-se de trabalhar com o aluno o seu texto para que ele atinja seus objetivos junto aos leitores a que se destina.

Dentre outros linguistas brasileiros que apostam em um ensino de Português contextualizado, Antunes é uma das que propõe um ensino de língua materna que extrapola os limites da terminologia gramatical e parte para um viés reflexivo. Para esta autora, a questão maior, em relação ao ensino de gramática, é "discernir sobre o objeto do ensino: as regras (mais precisamente, as regularidades) de como se usa a língua nos mais variados gêneros de textos orais e escritos" (ANTUNES, 2003, p. 88). Seguindo, de algum modo, esse mesmo viés, pode-se mencionar, dentre outros nomes, o do professor Travaglia, cuja proposta pedagógica para o ensino de Português nas séries iniciais do Ensino Fundamental, pautada nas concepções de alfabetização e letramento, será apresentada mais precisamente nas próximas seções deste artigo.

Há ainda aqueles estudiosos que defendem um ensino de gramática em uma perspectiva científica, como Borges Neto (2013), que, com base nas ideias de Perini ${ }^{10}$, afirma que cabe à escola qualificar os alunos em três conjuntos de conteúdos, quais

10 Borges Neto (2013) reproduz as ideias que estão nas Gramáticas de Perini (1995, 2010 e 2016), afirmando, em nota, que a interpretação final é de sua inteira responsabilidade. 
sejam: conteúdos essenciais (associados ao letramento, os quais são "úteis", indispensáveis para a vida cotidiana das pessoas), conteúdos culturais (de formação geral, indicadores de identidade sociocultural), e conteúdos de iniciação científica (de disciplina intelectual, de compreensão do mundo). Para Borges Neto (2013), o estudo da gramática possibilita o desenvolvimento nos alunos das habilidades de observação, de levantamento de hipóteses, de construção de sistemas explicativos, de testagem e avaliação das hipóteses levantadas, bem como da tentativa de explicá-las. Tais atividades, segundo o autor, são próprias da iniciação científica.

Posto isto, é certo que, mesmo com tantas propostas de ensino de Português em uma perspectiva funcional, o debate de como enfrentar pedagogicamente a atividade metalinguística ainda precisa avançar consideravelmente. O fato é que a maioria das propostas auxilia os professores de Português na clareza conceitual no que respeita à reconfiguração do ensino de natureza gramatical, jogando luzes para um avanço em direção a um ensino que extrapole a nomenclatura gramatical. No entanto, "os autores não escondem sua expectativa de que os professores, a partir dos poucos exemplos dados, ampliem e expandam por conta própria as propostas" (FARACO, 2017, p. 20). Isto é, as expectativas são lançadas, mesmo reconhecendo que há grandes problemas a serem superados no âmbito da educação linguística, como os de formação e do trabalho docente da escola básica brasileira.

Feitas essas discussões mais gerais, passa-se, na sequência, a considerações pontuais acerca da proposta de ensino de gramática de Travaglia (2013), na obra já mencionada.

\section{A proposta de ensino de gramática na obra Na trilha da gramática: conhecimento linguístico na alfabetização e letramento}

O levantamento de informações a respeito da formação intelectual de Luiz Carlos Travaglia"l faz-se necessário, uma vez que esses dados podem justificar e/ou corroborar as escolhas teóricas do autor, bem como o tipo de abordagem para o ensino de língua materna que ele realiza em suas propostas, sobretudo na obra em análise.

Luiz Carlos Travaglia fez seus estudos superiores na Universidade Federal de Uberlândia (UFU-MG), onde cursou Licenciatura Plena em Letras com habilitação em

11 As informações sobre Travaglia que constam neste artigo estão disponíveis no currículo Lattes e no site pessoal do autor, quais sejam: http://lattes.cnpq.br/043691150907624 e http://www.ileel.ufu.br/travaglia/. Acesso em: 25 maio 2020. 
Português e Inglês, em 1972. É mestre em Letras pela Pontifícia Universidade Católica do Rio de Janeiro (PUC-RJ), desde 1980; é doutor em Linguística pela Universidade Estadual de Campinas (UNICAMP), desde 1991, e pós-doutor em Linguística pela Universidade Federal do Rio de Janeiro (UFRJ), desde 2002. Sua área de atuação e de produção científica perpassa os domínios da Linguística Textual, concentrada no estudo do texto, do verbo, da tipologia textual, da coesão e coerência, do ensino de gramática, da análise linguística, do discurso e da gramaticalização. Atualmente, Travaglia é professor de Linguística e Língua Portuguesa e pesquisador do Instituto de Letras e Linguística da UFU-MG.

Como docente, dentre as disciplinas que o autor já ministrou, no âmbito da graduação e da pós-graduação, podem ser citadas as seguintes: Língua Portuguesa Sintaxe, Língua Portuguesa - Morfologia, Língua Portuguesa - Estilística, Língua Portuguesa - Semântica, Metodologia do Ensino de Língua Portuguesa, Linguística Aplicada ao Ensino de Língua Portuguesa, Linguística Aplicada ao Ensino de Língua Portuguesa, Tipos e gêneros textuais, Estudos da Significação: Semântica e Pragmática, Língua Portuguesa - A gramática nos livros didáticos, Tópicos em Linguística Aplicada I: Ensino de Gramática, Tópicos em Estudos Analítico-Descritivos I: Gramaticalização, Tópicos em Estudos Textuais 1: Tipologia Textual - Categorias de texto e sua caracterização. Já enquanto pesquisador do Instituto de Letras e Linguística da UFU-MG, o referido professor atua nas seguintes linhas de pesquisa: (i) Estudos textuais discursivos do Português e (ii) Estudos textuais discursivos e o ensino/aprendizagem de Língua Portuguesa.

Sua produção intelectual compreende um número significativo de livros publicados, organizados ou editados, dentre os quais pode-se destacar: O aspecto verbal no Português: a categoria e sua expressão (1981); Metodologia e prática de ensino da Língua Portuguesa (1984); Texto e coerência (1989); Gramática e interação: uma proposta para o Ensino de Gramática (1996); Gramática: ensino plural (2003) e Na trilha da gramática: conhecimento linguístico na alfabetização e letramento (2013). Além disso, o autor tem inúmeros artigos publicados em revistas especializadas e diversos capítulos de livros ${ }^{12}$.

A produção intelectual de Travaglia volta-se, basicamente, para o ensino de Língua Portuguesa, com foco no ensino de gramática. De posse destas informações contextuais, as discussões se voltarão, doravante, para a análise da obra Na trilha da gramática: conhecimento linguístico na alfabetização e letramento, publicada em 2013. A proposta desta obra é orientar os professores sobre o modus operandi do ensino de gramática nas séries iniciais do Ensino Fundamental, com foco em uma alfabetização e letramento

12 Informações disponíveis no site pessoal do autor, qual seja: http://www.ileel.ufu.br/travaglia/. Acesso em: 25 maio 2020. 
mais efetivos. Travaglia, diante disso, parte de princípios básicos para o ensino de língua materna e de gramática e termina com a prática de sala de aula por meio do que ele chama de "projetos", que seriam as atividades sobre tópicos diversos discutidos na obra. Essas atividades são elaboradas com bases em textos de fontes e gêneros diferentes.

Como já dito, a proposta ora analisada é voltada para as séries iniciais do Ensino Fundamental. Na ótica do autor, esse segmento de ensino apresenta importância vital, na medida em que possibilita a relação que o aluno terá com o estudo de sua língua materna durante toda a sua vida escolar. Além disso, afirma o professor que a qualidade da alfabetização e letramento viabilizados ao aluno o acompanhará sempre, possibilitandoIhe o domínio da língua escrita (ou não).

Em sua proposta, Travaglia (2013) pauta-se na definição de alfabetização e letramento postulada pelos Parâmetros Curriculares Nacionais - PCN (1998), os quais entendem por alfabetização, em seu sentido restrito, o "processo de aquisição da escrita alfabética" (BRASIL, 1998, p. 28) e, por letramento, o "produto da participação em práticas sociais que usam a escrita como sistema simbólico e tecnologia. São práticas discursivas que precisam da escrita para torná-las significativas, ainda que às vezes não envolvam as atividades específicas de ler ou escrever" (BRASIL, 1998, p. 21).

Além disso, Travaglia pauta-se, ainda, nas considerações de alfabetização e letramento feitas por Magda Soares, para quem estes dois processos são indissociáveis e interdependentes, haja vista que a alfabetização compreende "o ensino e o aprendizado de uma outra tecnologia de representação da linguagem humana, a escrita alfabéticoortográfica" (SOARES, 2005, p. 24), e o letramento "o conjunto de conhecimentos, atitudes e capacidades envolvidos no uso da língua em práticas sociais e necessários para uma participação ativa e competente na cultura escrita" (SOARES, 2005, p. 50).

Respaldado nessas duas concepções, o autor propõe uma sugestão sobre como trabalhar com o conhecimento linguístico, a partir do desenvolvimento de atividades, visando à aquisição de conhecimentos linguísticos concernentes à gramática da língua e que sejam pertinentes para a alfabetização e o letramento nas séries iniciais. Com essa proposta, Travaglia busca mostrar que o conhecimento linguístico não se reduz apenas à teoria gramatical/linguística e terminologia para analisar os elementos da língua, de modo descontextualizado. Acrescenta, ainda, que este conhecimento teórico, a partir do que sugere, deve acontecer em conjunto com todas as atividades que ele apresenta, as quais são desenvolvidas com o objetivo de que o aluno:

a) adquira a variedade escrita da língua, uma vez que ele domina uma variedade oral familiar quando chega à escola e 
- O ensino de gramática a partir da análise da proposta pedagógica de Luiz Carlos Travaglia

b) alcance progressivamente o domínio e a capacidade de uso de um número cada vez maior de recursos da língua, tornando-se um usuário da língua progressivamente mais competente. (TRAVAGLIA, 2013, p. 12).

Dessa forma, Travaglia espera, de acordo com a sua exposição de motivos, que as sugestões das atividades possam ser úteis, produtivas e que sejam um suporte para um ensino que fuja à tradição que circunda o ensino básico nas escolas de Ensino Fundamental do Brasil, levando os alunos a adquirir habilidades de uso da língua, em suas diferentes variedades. Importante, ainda, destacar que o autor estabelece que uma de suas opções para a construção de uma metodologia "é trabalhar sempre no nível textual-discursivo da língua" (TRAVAGLIA, 2013, p. 14).

A fim de atender esses objetivos, a obra está organizada em quatro capítulos. No capítulo 1, Travaglia apresenta alguns pontos que julga ser fundamentais para o professor de Português poder realizar um ensino mais produtivo tanto nas séries iniciais e em todas as demais; além de apresentar opções metodológicas concernentes à sua proposta.

No capítulo 2, consta o conjunto básico de conhecimentos linguísticos que o autor julga conveniente para ser trabalhado nas séries iniciais do Ensino Fundamental, conhecimentos linguísticos estes que serão descritos na seção subsequente. Além disso, neste capítulo, Travaglia propõe uma forma de abordar todos estes conhecimentos, por meio de "projetos", que consistem em exemplos de atividades de ensino e aprendizagem, segundo o autor, "eficientes" para auxiliar a alfabetização e o letramento. A estratégia dos "projetos", na ótica de Travaglia (2013, p. 13), se concentra "sobretudo em discutir como os diferentes recursos da língua contribuem para o sentido de cada texto na situação em que é usado, ou seja, na prática social a que serve". Esses projetos, além do mais, devem ser organizados pelos professores para atender a um conjunto de princípios que regem a atividade em sala de aula, no intuito de atingir determinados objetivos relacionados ao ensino e à aprendizagem.

No capítulo 3, há uma continuidade das atividades, as quais foram elaboradas a partir de textos de gêneros variados, textos que o autor define como "concretos", seguindo um nível de análise textual-discursiva.

Já o capítulo 4 mostra possibilidades de se organizar e trabalhar o conhecimento linguístico acerca do léxico, focando na ampliação e no uso do vocabulário dos alunos, haja vista que Travaglia acredita que o desenvolvimento da competência lexical é essencial para um letramento efetivo. 
É válido pontuar que, em alguns momentos e no final de cada capítulo, o autor propõe algumas leituras complementares destinadas aos professores, a fim de aprofundarem mais sobre os conteúdos discutidos em cada capítulo. Além do mais, há indicações de alguns livros para alunos, com o objetivo de reforçar, nas palavras do autor, a leitura, visto que esta é colocada como ponto fundamental no trabalho com o conhecimento linguístico.

Antes, porém, de iniciar a análise e discussão dos dados, é preciso estabelecer os critérios de seleção do conteúdo a ser analisado no respectivo artigo ${ }^{13}$. Elegeu-se, para tanto, um tópico que cumpre critérios ${ }^{14}$ relevantes dentro da obra, a "progressão" e a "frequência". Este está relacionado à regularidade com que o conteúdo a ser ensinado ou aprendido pelo aluno tem mais probabilidade de ser usado por ele. Já a "progressão" considera a frequência com que determinado conteúdo aparece, em diferentes níveis de complexidade e com a mesma função ou valor em diferentes contextos. Neste caso, o tópico selecionado foi "o ensino da comparação", no qual o autor apresenta, inclusive, uma proposta de abordagem do conteúdo por meio de "projetos".

Posto isto, segue-se, nas próximas linhas, uma apresentação da proposta do autor sobre o ensino da comparação.

\section{Proposta para o ensino da comparação na obra Na trilha da gramática: conhecimento linguístico na alfabetização e letramento}

O ponto de partida da análise apresentada mais à frente é a ideia de que o ensino de gramática, como parte do ensino de Língua Portuguesa, pode contribuir para o desenvolvimento do processo de alfabetização e, principalmente, de letramento, considerando que o desenvolvimento do conhecimento linguístico promove uma melhora nas habilidades de língua escrita e de língua oral, de modo que o foco seja nos processos funcionais que envolvem a significação, os princípios e as regras da língua.

De modo geral, o autor busca, no decorrer da obra, deixar clara a importância que o conhecimento linguístico tem, em todos os planos e níveis da língua, para promover a alfabetização e o letramento dos alunos. Importante ressaltar a quantidade

13 Travaglia (2013) traz, em sua obra, uma lista com quinze tópicos, que se subdividem em setenta e quatro subtópicos, de conteúdos linguístico-gramaticais envolvidos no processo de alfabetização e letramento nas séries iniciais do Ensino Fundamental.

14 Travaglia (2013) aponta, na obra, critérios metodológicos responsáveis por tornar o ensino/aprendizagem mais produtivo e organizado, quais sejam: abrangência, organização, seleção, progressão, frequência, complexidade e extensividade. Para este artigo, foram usados os critérios de frequência e progressão. 
- O ensino de gramática a partir da análise da proposta pedagógica de Luiz Carlos Travaglia

de conteúdos mínimos ${ }^{15}$ mobilizados por Travaglia (2013) para embasar suas ideias e de como a disposição deles mostra para o professor o que tratar e como proceder com as atividades. Um exemplo disso é quando o autor destaca, para o ensino de comparação, que os exercícios "não devem nem podem ser desenvolvidos todos em seguida, em um único bloco. O ideal é que sejam desenvolvidos ao longo de um ano ou ao longo de vários anos, por exemplo, do $1^{\circ}$ ao $5^{\circ}$ anos" (p. 115) ou quando apresenta exemplos de atividades que fazem os alunos refletirem sobre os vários modos de se comparar. Na obra, tem-se os seguintes exemplos (TRAVAGLIA, 2013, p. 117, grifos do autor):

(1) Jotinha falou feito o vovô

(2) Jotinha falou igualzinho/igual o vovô

(3) Jotinha falou que nem o vovô

(4) Jotinha falou como o vovô.

Entretanto, em nenhuma das atividades propostas, inclusive nos exemplos supracitados, o autor evidencia a série na qual deveria ser aplicada a atividade, fator que poderia dificultar a execução do projeto, tendo em vista não só a quantidade de conteúdos com os quais o professor se depara, mas também o conhecimento linguístico (teórico e metodológico) que ele deve mobilizar para organizar e selecionar os conteúdos, de modo que haja uma progressão por nível de complexidade entre eles.

Sobre este aspecto, faz-se relevante destacar o fato de o autor partir do pressuposto de que os professores das séries iniciais, que são pedagogos na sua maioria, detêm um arsenal teórico de referência baseado em estudos linguísticos/gramaticais. Desse modo, Travaglia (2013) afirma que, para o ensino de conhecimento linguístico acontecer de modo eficaz, o professor precisa conhecer as três concepções básicas de gramática ${ }^{16}$, tendo consciência do que é cada uma e como ela pode ser utilizada no trabalho em sala de aula.

15 Travaglia (2013, p. 60, grifos nossos) apresenta um levantamento do que julga ser pertinente a ser trabalhado em termos de conhecimentos linguísticos, "como um mínimo a ser abordado nas séries iniciais do Ensino Fundamental".

16 As três concepções básicas de gramática a que o autor faz referência são: Gramática teórica (teoria linguística ou gramatical que busca dizer como é o mecanismo da língua, como a língua é constituída e como funciona. Pode possibilitar ao professor a seleção dos recursos linguísticos que vai ensinar, além de ajudá-lo a organizar o ensino); Gramática internalizada (mecanismo da língua que está em nossa mente e que nos permite usar a língua em situações de interação comunicativa); Gramática normativa (que nos dá as regras de uso da língua e suas variedades. Deve ser trabalhada a fim de orientar os alunos quanto ao uso das muitas variedades da língua nos diferentes tipos de situação) (TRAVAGLIA, 2013, p. 33-34). 
Ademais e reforçando essa ideia, o autor ressalta que o professor, ao montar um material de trabalho, deve perseguir um "ecletismo teórico", isto é, não pode pautar-se em uma corrente teórica específica. Assim, nas palavras do autor:

Nessa tarefa, certamente não será produtivo limitar-se a nenhuma teoria ou corrente de estudo (Estudos tradicionais de língua ou Gramática tradicional, Estruturalismo, Gerativismo, Análise da Conversação, Linguística Textual, Estilística, Teoria Literária, Análise do Discurso, Gramática Funcional, Semântica Argumentativa etc.), mas usar o que todas nos mostram a respeito do funcionamento linguístico dos elementos envolvidos no tópico a trabalhar. (TRAVAGLIA, 2013, p. 97).

Pode-se depreender, então, que o professor das séries iniciais, para desenvolver a alfabetização e o letramento dos alunos por meio de conteúdos linguísticos, tem de ter uma formação que contemple, mesmo que minimamente, noções teóricas relacionadas à Linguística, o que, muitas vezes, não é a práxis. Simionato e Spessatto Bortolanza (2009, p. 1106), ao discutirem sobre a formação dos professores no curso de Pedagogia, especificamente sobre o ensino de Língua Portuguesa nas séries iniciais, afirmam:

Também devemos considerar que a falta de disciplinas específicas sobre o ensino da linguagem, comprometem $[s i c]$ o processo de formação. Na pesquisa há alguns indicadores que o Programa do curso de Pedagogia, neste contexto pesquisado, não contempla boa parte das questões que emergem das práticas escolares nas séries iniciais, para o ensino da Língua Materna, a carga horária do curso, multifacetada num excessivo número de disciplinas, é outro agravante que contribui para a pouca eficiência deste. O desdobramento do tempo, neste sentido, provoca o esfacelamento e uma abordagem muito breve e superficial dos conteúdos fundamentais para a formação desses educadores, aliado à pouca competência técnico-científica dos formadores.

O que as autoras atestam é a dificuldade que os professores têm, durante a sua formação, de adquirir uma formação acadêmica necessária para estarem habilitados no que diz respeito a teorias ligadas à Linguística, logo, a perseguição por um "ecletismo teórico", como sustenta Travaglia (2013), poderia ficar comprometida pela própria formação dos professores responsáveis pelas séries iniciais.

No próximo tópico, passa-se às análises do conteúdo relacionado ao "ensino da comparação", em razão da grande quantidade de assuntos presentes na obra analisada. 


\section{O ensino da comparação na obra Na trilha da gramática: conhecimento linguístico na alfabetização e letramento: análise propriamente dita}

Será examinado mais detidamente o que a obra de Travaglia nos diz sobre a comparação. As análises que serão realizadas neste momento partem da ideia difundida pelo autor de que o letramento envolve uma grande quantidade de conteúdos linguísticos e gramaticais que podem tanto estar relacionados ao domínio da variedade escrita da língua, como da variedade oral.

Para tanto, o professor é considerado o responsável por, de maneira explícita ou não, trabalhar com os alunos a habilidade de refletir linguisticamente, seja na produção ou compreensão de textos. Para o autor, o professor deve manter uma visão crítica no sentido de não trabalhar com dados isolados, mas sempre contextualizados; ter uma visão global sobre os conteúdos trabalhados e manter uma visão funcional com relação ao conhecimento abordado, não esquecendo da complexidade inerente a cada conhecimento trabalhado.

No que diz respeito especificamente ao conteúdo de comparação, é apresentado na obra um "projeto", em forma de atividade, que se constitui como "estratégias" direcionadas às primeiras séries do Ensino Fundamental ${ }^{17}$. Importante salientar que a teoria que embasa de modo mais sistemático a proposta do livro, apesar de não ser a única, é aquela relacionada ao letramento, que, como já dito, foca na dimensão social e busca uma conexão entre a linguagem e a vida, o que, salvos alguns momentos no livro, não é posto em evidência. Para ilustrar, tem-se o seguinte exemplo da atividade sobre Modos de comparar:

\footnotetext{
17 De acordo com Travaglia (2013, p. 116): “Não nos preocupamos em dizer se a atividade é para o $1^{\circ}, 2^{\circ}, 3^{\circ}$, $4^{\mathrm{o}}$ ou $5^{\circ}$ ano, pois isto depende muito do desenvolvimento dos alunos e é o professor quem precisa decidir isto, apesar de, em coleções de material didático, haver sempre uma progressão entre os diversos momentos de um ano e os diferentes anos".
} 
B) Nos exercícios do capítulo anterior, você viu como comparar usando as palavras como, feito, igualzinho, igual e que nem, indicando semelhança. Veja, nos exemplos abaixo, tirados dos textos 7 e 4, que a palavra parecer também pode ser usada para comparar indicando semelhança:

“Nas últimas aulas, a Onça pulava com rapidez e agilidade - parecia um gato gigante." (T7)

"Aquele texto não se parecia com um anúncio, até eu achava." (T4)

Veja outros exemplos:

» Você parece um coelhinho, adora comer cenoura.

»Carregando as carteiras, os meninos pareciam formigas trabalhadeiras.

» Com esta roupa, papai vai parecer o palhaço Pipoca.

» Gritando daquele jeito você pareceu um doido.

Agora você. Use a palavra parecer em frases, fazendo comparações.

Exemplo: Vou parecer o Super-Homem com essa roupa.

a)

b)

c)

Fonte: Travaglia (2013, p. 118-119)

Percebe-se, no exercício acima apresentado, um claro objetivo de levar o aluno a treinar tipos de estrutura, com base em um modelo indicado, de modo a promover nele, considerando que este seja capaz de criar novos enunciados, a habilidade de automatizar o respectivo recurso, no intuito de produzir e reconhecer os significados e valores por trás de determinada escolha. Entretanto, o referido exercício, assim como muitos outros, não apresenta uma clara articulação com a proposta da obra, no que diz respeito às considerações sobre alfabetização e letramento ${ }^{18}$, já que o exercício se apresenta com foco na ordem da estrutura. Ademais, a produção escrita do aluno parece não ter nenhuma função social, não sendo, portanto, sujeito de suas produções e de sua aprendizagem.

Abaixo, tem-se outro exemplo de exercício apresentado no livro:

18 Magda Soares (2004, p. 14-15) entende a alfabetização e o letramento como práticas distintas, apesar de indissociáveis, assim, enquanto este caracteriza-se como "incidental, indireto e subordinado a possibilidades e motivações da criança", aquela caracteriza-se como "direto, explícito e sistemático" (op. cit., p. 11). 
- O ensino de gramática a partir da análise da proposta pedagógica de Luiz Carlos Travaglia

(41) A) Abaixo temos um trecho do texto "Alegria" (T2), um pouco modificado:

As crianças logo perceberam que o mundo, colorido, era muito mais bonito que o mundo cinzento e isso as deixava muito felizes. (T2)

a) O texto anterior está fazendo uma comparação?

Resposta: sim

b) Se tiver fazendo comparação, é uma comparação:

$$
\text { ( ) de semelhança ( ) de diferença }
$$

Resposta: de diferença

Fonte: Travaglia (2013, p. 125-126).

Para ser exato, o autor propõe 19 (dezenove) exercícios sobre o estudo da comparação ${ }^{19}$, todos eles seguem o estilo dos exercícios já apresentados nesta seção, os quais trazem uma abordagem estrutural.

$\mathrm{Na}$ introdução da obra, Travaglia (2013) deixa clara a sua filiação às teorias do letramento. No entanto, o que prevalece nos exercícios propostos, de modo sistemático, é uma abordagem estruturalista. Isso aponta para uma certa incongruência. Por um lado, tem-se uma tentativa de propor um material sobre como fazer um ensino de gramática nas séries iniciais do Ensino Fundamental com foco em uma alfabetização e letramento mais efetivos, em suas múltiplas faces. Por outro lado, a referência explícita nas atividades segue exercícios de base estrutural, os quais não dão conta de desenvolver, nos alunos, o domínio da variedade escrita da língua, que é tão enfatizado pelo autor.

Em obra intitulada Metodologia e prática de ensino da Língua Portuguesa, Travaglia, Araújo e Alvim (2007) discutem questões relacionadas ao tratamento dado ao ensino, especialmente aos aspectos relacionados à norma gramatical, ao reconhecimento de variedades linguísticas, às várias teorias que embasam os trabalhos linguísticos etc. Vale frisar que, no texto supramencionado, os autores filiam-se ao estruturalismo enquanto

19 Foram contabilizados apenas os exercícios presentes no capítulo 2, intitulado "Conhecimentos linguísticos: o que ensinar e como ensinar - Trabalhando com projetos de ensino", no qual o autor apresenta um projeto com atividades para o ensino de comparação, correspondendo a 24 páginas do livro. 
corrente teórica e metodológica para o ensino de língua materna, o que se confirma nas 237 páginas do texto com inúmeros exemplos que corroboram a perspectiva apresentada, como é possível verificar no exemplo a seguir, em que os autores versam sobre o conteúdo da comparação:

[...] Com relação a este último aspecto temos um exemplo para maior clareza. No Português, pode-se exprimir a comparação de similaridade usando as seguintes palavras ou locuções: que nem, igual, tal qual, feito, como. Exemplo:

(c) Ela está como uma onça.

(d) Ela está tal qual uma onça.

(e) Ela está feito uma onça.

(f) Ela está igual uma onça.

(g) Ela está que nem uma onça.

Fonte: Travaglia, Araújo e Alvim (2007, p. 58)

O que se quer mostrar, ao trazer a proposta do livro, é que Travaglia já tinha uma tendência a usar uma abordagem estruturalista em outros trabalhos, abordagem essa que é, de certa forma, imprimida pelo autor nos exercícios propostos em Na trilha da gramática: conhecimento linguístico na alfabetização e letramento, o que não condiz com o objetivo desta obra. O autor, ao fazer referência à Travaglia, Araújo e Alvim (2007), afirma que, nas séries iniciais do Ensino Fundamental, o conteúdo de concordância, por exemplo, pode ser trabalhado com exercícios de repetição, substituição ou transformação, "que podem ser feitos oralmente e/ou por escrito, para ajudar o aluno a dominar a forma culta e mesmo automatizá-la, mas regras de concordância não serão dadas teoricamente" (TRAVAGLIA, 2013, p. 44).

Ainda em relação ao ensino da comparação, o autor também aposta nos exercícios estruturais como forma de os alunos entenderem o grau comparativo dos adjetivos, conforme se pode observar a seguir. 
- O ensino de gramática a partir da análise da proposta pedagógica de Luiz Carlos Travaglia

(42) A) Fazer o exercício oral que o professor vai dar.

Professor(a), os exercícios a seguir são exercícios estruturais sobre o grau comparativo dos adjetivos. O aluno não terá em mãos o material abaixo e o exercício se faz oralmente. Aqui é só um exemplo do que você pode fazer?

1) Repetição

P - As crianças são mais amigas do palhaço do que os adultos.

A - Repete

P - Os adultos são menos amigos do palhaço do que as crianças.

A - Repete

$P$ - As crianças são tão amigas do palhaço quanto os adultos.

A - Repete

P - Eu sou tão alegre quanto o palhaço.

A - Repete

$\mathrm{P}$ - Eu sou menos alegre que o palhaço.

Fonte: Travaglia (2013, p. 128)

É preciso chamar a atenção para o fato de que, quando se pensa em uma proposta de ensino de gramática com ênfase em uma alfabetização e letramento, o autor não consegue manter uma progressão, no sentido de expandir os exercícios que, como já mostrado, são essencialmente de base estrutural em sua grande maioria, para outras atividades que levem o aluno a um efetivo desenvolvimento da modalidade escrita da língua, haja vista que a obra não apresenta nenhum modelo de atividade que mobilize práticas sociais de escrita mais direcionada. Isto é, o autor solicita por 22 (vinte e duas) vezes que o aluno escreva frases descontextualizadas, com base em modelos indicados previamente, de modo que ele automatize o recurso em estudo.

Agora escreva duas frases fazendo comparação de igualdade entre dois seres, usando tão... quanto ou tão...como. Cada um lê uma comparação feita e os colegas e o(a) professor(a) dizem se ficou bem feita:

a)

b)

Fonte: Travaglia (2013, p. 123) 
É importante frisar que a proposta de Travaglia (2013) é voltada para as séries iniciais do Ensino Fundamental, do $1^{\circ}$ ao $5^{\circ}$ ano. Tendo em vista isso, é muito possível que, partindo de uma ideia de progressão, como o próprio autor propõe, e considerando que o professor deve usar uma abordagem adequada a cada nível, até o último ano do Ensino Fundamental, o aluno já tenha condições de partir para atividades que o desafiem mais em termos de produção escrita, embora não se deixe de reconhecer que, na realidade da educação básica brasileira, muitos alunos chegam ao final do referido ciclo sem saber ler ou com pouca habilidade de escrita.

Nesse sentido, tendo em vista que um dos focos mais evidentes da proposta de Travaglia, por meio dos exercícios propostos, é a aquisição/desenvolvimento/domínio da variedade escrita da língua, baseado nas concepções de alfabetização e de letramento, percebe-se que há pouca concretização da proposta do autor no sentido de apresentar atividades que cumpram esse objetivo de modo mais efetivo.

Na obra, o autor propõe algumas atividades que se concentram na significação dos recursos linguísticos, na sua contribuição para os sentidos que se quer veicular por meio dos textos, bem como na exploração de recursos diversos para o mesmo fim, de modo a ressaltar a diferença entre eles (quando possível). Um exemplo disso é quando o autor orienta os professores a como abordar, por exemplo, os diferentes aspectos envolvidos no uso da comparação para expressar sentidos diversos nos textos ou quando trabalha aspectos da variação linguística nas primeiras séries, sugerindo que sempre pode haver outras possibilidades de palavras com o mesmo sentido ou, ainda, quando propõe que o professor trabalhe com a figura de linguagem metáfora, como um recurso de comparação. Dentre os exemplos, chama-se atenção para a seguinte amostra:

B) No almoço tinha macaxeira com carne moída. Adoro.

A palavra macaxeira é muito usada no Nordeste do Brasil para falar de uma planta que faz parte da nossa alimentação. Essa planta tem outros nomes em outras regiões. Você conhece outros nomes de macaxeira? Se sim, diga-os. Se não, veja se você descobre outros nomes dessa planta. Se preciso, use o dicionário.

Fonte: Travaglia (2013, p. 129)

Esse tipo de atividade, por exemplo, apresenta alguma funcionalidade, no sentido de levar o aluno a conhecer e refletir sobre outras possibilidades de palavras com sentido equivalente àquele da sua região ou realidade linguística. 
- O ensino de gramática a partir da análise da proposta pedagógica de Luiz Carlos Travaglia

Feitas as análises e as discussões da proposta de ensino da "comparação" na obra de Travaglia (2013), a seguir, serão apresentadas algumas considerações acerca deste estudo.

\section{Considerações finais}

O estudo ora realizado neste artigo não teve a pretensão de apresentar uma avaliação definitiva, nem, tampouco, trata-se de um juízo de valor sobre a obra Na trilha da gramática: conhecimento linguístico na alfabetização e letramento, de Travaglia (2013). De todo modo, buscou-se, pontualmente, realizar uma análise da exequibilidade ou não da proposta do autor, no sentido de promover a ideia de que o ensino de gramática pode contribuir para o desenvolvimento do processo de alfabetização e, principalmente, de letramento.

Entretanto, é pertinente afirmar que a proposta deste autor, embora estabeleça um avanço teórico no debate de como enfrentar pedagogicamente a atividade metalinguística, sobretudo quando apresenta uma exposição de motivos pautada em teorias que privilegiam o nível textual-discursivo e social da língua, não cumpre, efetivamente, o objetivo geral da obra (desenvolver a competência comunicativa dos alunos), haja vista que o que de fato prevalece são exercícios de cunho estruturalista que pouco estimulam o desenvolvimento das habilidades de leitura e de escrita como práticas sociais. Isso porque, do ponto de vista do letramento, as atividades apresentadas por Travaglia (2013) não estão condizentes com um ensino de gramática sensível às questões exteriores à sala de aula, visando às experiências socioculturais dos alunos, que devem ser refletidas nas práticas sociais de leitura e de escrita.

Em síntese, o que se percebe é que a proposta de Travaglia (2013), embora haja um esforço por parte do autor em oferecer uma possibilidade para o ensino de natureza gramatical nas séries iniciais do Ensino Fundamental, não consegue preencher as lacunas apontadas acima, no sentido de sistematizá-la, de modo a superar as asserções mais gerais, o que viabilizaria ao professor um material que tivesse funcionalidade e que fosse coerente com os objetivos ora estabelecidos, que vão além de fornecer exemplos do que poderia ser feito.

Não se pode dissociar o letramento da alfabetização tendo em vista que para haver letramento é preciso pensar o ensino da leitura e da escrita dentro de um contexto vinculado à produção de sentidos que façam parte da vida do aluno. 
Partindo do que o próprio autor propõe na sua exposição de motivos da obra em tela, isto é, promover o ensino de gramática nas séries iniciais do Ensino Fundamental com foco em uma alfabetização e letramento mais efetivos, uma proposta, então, seria pensar na ampliação dessas atividades, de modo que estas visassem, de fato, ao desenvolvimento do domínio de práticas de leitura e de escrita, além da oralidade, por meio de gêneros textuais diversos, levando em conta a realidade dos alunos, bem como considerando suas dificuldades e habilidades. Nesse sentido, uma saída possível seria dar uma maior funcionalidade às atividades, enfatizando a leitura, a compreensão e a produção escrita de textos diversos, como poemas, notícias, reportagens, textos científicos, receitas, histórias em quadrinhos, charges, propagandas, classificados, encartes de preços, jogos interativos, lúdicos e pedagógicos (como sudoku), cruzadinhas, jogos dos sete erros, dentre outros, relacionados à realidade social dos alunos, de um modo geral.

No caso do estudo da comparação, conteúdo este que foi analisado mais detidamente neste artigo, uma proposta seria extrapolar os limites das atividades estruturais, - as quais se voltam exclusivamente para a leitura e escrita de frases soltas colocando os gêneros textuais diversos como foco de análise. Essa atitude promoveria um maior envolvimento dos alunos com práticas reais de leitura, de compreensão e da produção (escrita e oral) de textos, valorizando o seu conhecimento linguístico e a sua realidade social. A título meramente ilustrativo, será apresentada, a seguir, uma proposta possível sobre como abordar o ensino de gramática nas séries iniciais do Ensino Fundamental, partindo do próprio fenômeno linguístico eleito pelo autor em análise. 


\section{PROPOSTA DE ATIVIDADE}

- Leia o seguinte bilhete deixado na geladeira da casa de Marília, por seu primo Paulo.

Marília, bom dia!

Queria muito dizer que gostei muito da sobremesa de morango que você fez. O doce ficou bom que nem o da vovó. Amei!

Abraço,

Paulo.

- Você percebeu que, ao elogiar o doce feito pela prima Marília, Paulo faz uma comparação entre a sobremesa feita pela prima com a que a sua avó também faz, estabelecendo um efeito de sentido positivo.

- Agora, no espaço abaixo, produza um pequeno bilhete, apresentando uma situação do seu dia a dia, em que você faz uso de uma comparação. Você pode comparar algo entre você mesmo e o(a) seu(sua) irmão(ã), ou primo(a), ou algum(a) amiguinho(a). Capriche!

Fonte: Atividade proposta pelos autores deste artigo

Esse tipo de atividade é importante porque é muito mais provável que o discente consiga visualizar sentido naquilo que ele está estudando, entendendo que a língua é usada como uma forma de interação, a fim de se agir na sociedade.

Considerando-se o percurso histórico realizado neste estudo, acerca do ensino de gramática na educação linguística, de um modo mais geral, e trazendo, posteriormente, para o contexto brasileiro, é nítido que, ao longo do tempo, muitas concepções de ensino de língua coexistiram, ora colocando a gramática como o centro do processo de ensino e aprendizagem, ora colocando-a como um componente auxiliar, articulado às habilidades de escrita, leitura e oralidade. A coexistência dessas concepções de ensino de língua materna permanece ainda em dias atuais, sobressaindo-se a tendência tradicionalista.

Nesse sentido, as propostas de ensino de Português, de fato, estão circulando e, em muitas delas, como na de Travaglia (2013), há o que se pode efetivar em sala de aula, com a devida orientação do professor treinado para isso. No entanto, faltam ainda condições para torná-las viáveis, dentre as quais, algumas fogem ao alcance direto dos envolvidos no processo, como, por exemplo, (i) a melhoria das condições de trabalho 
no magistério; (ii) a formação de professores, no sentido de oferecer possibilidades de efetiva prática de análise científica de fatos da língua; (iii) o próprio preenchimento das lacunas das tantas propostas de ensino que concorrem no atual contexto, como a de Travaglia (2013). Faraco (2017, p. 21) afirma que, para o preenchimento dessas lacunas, o esforço "não poderá jamais ser apenas individual, mas terá de ser coletivo, envolvendo necessariamente, nesse coletivo, os professores de educação básica".

Tais lacunas, na sistematização das propostas para o ensino de Português, têm efeitos nem tanto positivos, uma vez que "de um lado, dificultam a formação dos professores e, do outro, inviabilizam uma interação produtiva com os professores já em exercício" (FARACO, 2017, p. 21). O resultado disso está relacionado ao fato de que muitos professores acabam optando pela zona de conforto oportunizada pela segurança do ensino tradicional, embora reconheçam e critiquem a sua ineficácia, bem como ao fato de que continuam reproduzindo a tradição, que é assegurada pela maioria dos livros didáticos.

\section{Referências}

ANTUNES, I. Aula de português: encontro e interação. São Paulo: Parábola Editorial, 2003.

BORGES NETO, J. Ensinar gramática na escola? ReVEL, edição especial, n. 7, 2013. Disponível em: www.revel.inf.br. Acesso em: 05 dez. 2019.

BORGES NETO, J. História da Gramática. Curitiba, 2018 (no prelo).

BRASIL. Base Nacional Comum Curricular (BNCC). Educação é a Base. Brasília, MEC/ CONSED/UNDIME, 2017. Disponível em: http://basenacionalcomum.mec.gov.br/ images/BNCC_publicacao.pdf. Acesso em: 02 dez. 2019.

BRASIL. Parâmetros Curriculares Nacionais: $3^{\circ}$ e $4^{\circ}$ ciclos do Ensino Fundamental: Língua Portuguesa. Brasília/DF: MEC/SEF, 1998.

COSTA-HÜBES, T. C. Uma tentativa de análise linguística de um texto do gênero "relato histórico". Linguagem em (Dis)curso, Palhoça, v. 10, n. 1, p. 181-205, jan./abr. 2010. Disponível em: https://www.researchgate.net/publication/44897350_Uma_tentativa_ de_analise_linguistica_de_um_texto_do_genero_'relato_historico'. Acesso em: 27 nov. 2019. 
- O ensino de gramática a partir da análise da proposta pedagógica de Luiz Carlos Travaglia

FARACO, C. A. Ensinar x Não ensinar gramática: ainda cabe essa questão? Caledoscópio, Rio Grande do Sul, v. 4, n. 1, p. 15-26, 2006. Disponível em: http://revistas.unisinos.br/ index.php/calidoscopio/article/view/5983. Acesso em: 17 dez. 2019.

FARACO, C. A. Gramática e ensino. Diadorim, Rio de Janeiro: Revista 19, v. 2, p. 11-26, 2017. Disponível em: https://revistas.ufrj.br/index.php/diadorim/article/view/14443. Acesso em: 27 nov. 2019.

GERALDI, J. W. O texto em sala de aula. São Paulo: Ática, 2011 [1997].

LEITE, M. Q. Tradição, invenção e inovação em gramáticas da língua portuguesa séculos XX e XXI. In: NEVES, M. H. de M.; CASSEB-GALVÃO, V. C. (org.). Gramáticas contemporâneas do português: com a palavra, os autores. São Paulo: Parábola Editorial, 2014. p. 115-133.

MATTOS E SLVA, R. V. O português são dois... novas fronteiras, velhos problemas. São Paulo: Parábola Editorial, 2004.

NEVES, M. H. M. Gramática do Português revelada em textos. São Paulo: Editora UNESP, 2018.

PERINI, M. A. Gramática descritiva do português brasileiro. Rio de Janeiro: Vozes, 2016.

PERINI, M. A. Gramática descritiva do português brasileiro. Rio de Janeiro: Vozes, 2010.

PERINI, M. A. Gramática descritiva do português. São Paulo: Ática, 1995.

SIMIONATO, M. M.; SPESSATTO BORTOLANZA, M. O processo de formação no curso de pedagogia: reflexões sobre o ensino da língua portuguesa nas séries iniciais. In: IX Congresso Nacional de Educação - EDUCERE. PUCPR, 2009. Disponível em: https:// educere.bruc.com.br/arquivo/pdf2009/2070_1036.pdf. Acesso em: 02 dez. 2019.

SOARES, M. Letramento e alfabetização: muitas facetas. Revista Brasileira de Educação, n. 25, p. $5-17,2004$.

SOARES, M. Alfabetização e letramento: caderno do professor. Belo Horizonte: UFMG, 2005. 
TRAVAGLIA, L. C. Na trilha da gramática: conhecimento linguístico na alfabetização e letramento. São Paulo: Cortez, 2013 (Coleção Biblioteca Básica de Alfabetização e Letramento).

TRAVAGLIA, L. C.; ARAÚJO, M. H. S.; ALVIM, M. T.F. Metodologia e prática de ensino de língua portuguesa. 4. ed. rev. Uberlândia: EDUFU, 2007. Disponível em: https://www. researchgate.net/publication/331191695_METODOLOGIA_E_PRATICA_DE_ENSINO_ DA_LINGUA_PORTUGUESA. Acesso em: 04 dez. 2019.

VIEIRA, F. E. Gramáticas brasileiras contemporâneas do português: linhas de continuidade e movimentos de ruptura com o paradigma tradicional de gramatização. 2015. Tese (Doutorado em Letras) - Centro de Artes e Comunicação, Universidade Federal de Pernambuco, Recife, 2015.

VIEIRA, F. E. A gramática tradicional: história crítica. São Paulo: Parábola, 2018.

COMO CITAR ESTE ARTIGO: ANJOS, Marcelo Alessandro Limeira dos; OLIVEIRA, Meryane Sousa; SILVA, Raimunda da Conceição. O ensino de gramática a partir da análise da proposta pedagógica de Luiz Carlos Travaglia. Revista do GEL, v. 17, n. 2, p. 36-60, 2020. Disponível em: https://revistadogel.gel.org.br/

DOI: http://dx.doi.org/10.21165/gel.v17i2.2844

Submetido em: 03/06/2020 | Aceito em: 30/07/2020. 